\title{
Tomas Torres, COMUNIDAD Y ESTADO EN ALVARO GARCÍA LINERA. UN ANÁLISIS A TRAVÉS DE SUS LUGARES DE ENUNCIACIÓN (1988 - 2017).
}

Santiago de Chile, Ariadna ediciones (2018)

\section{J. Fabian Cabaluz D. ${ }^{1}$}

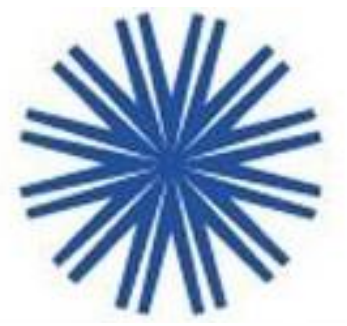

De acuerdo a los planteamientos de Antonio Gramsci, una de las funciones del trabajo intelectual, y particularmente de quienes son considerados como intelectuales orgánicos de las clases dominadas, consiste en cultivar la memoria histórica y colectiva de su clase social, lo cual implica entre otras cosas, labrar sus experiencias de lucha, formas organizativas, repertorios de acción, concepciones de mundo, proyectos emancipatorios y todo el acumulado conceptual, teórico-político e histórico de su clase.

Considerando lo anterior, creemos que el libro Comunidad y Estado en Álvaro García Linera. Un análisis a través de sus lugares de enunciación (1988 - 2017) del sociólogo Tomás Torres López, es un esfuerzo que se inscribe en el trabajo realizado por un número importante de intelectuales, investigadores/as y militantes de América Latina, que velan por mantener vivas, en el campo político y cultural, las formulaciones conceptuales, teóricas y prácticas del marxismo crítico latinoamericano.

Considerando lo anterior, nos interesa señalar tres grandes temáticas desplegadas en el libro y que pueden ser de interés para quienes cultivan las ciencias sociales y las humanidades desde América Latina.

En primer lugar, el libro se posiciona, siguiendo los planteamientos de Michael Löwy, desde la perspectiva de la sociología de los intelectuales revolucionarios, lo que le permite analizar con rigurosidad la obra de Álvaro García Linera; sus planteamientos ideológicos y políticos; la vinculación de sus formulaciones teórico-políticas con la realidad histórico concreta de

\footnotetext{
${ }^{1}$ Universidad Academia de Humanismo Cristiano. E-mail: fabiancabaluz@gmail.com
} 
Bolivia y América Latina; la influencia de coyunturas y acontecimientos históricos en su producción conceptual; y la relación del contenido de su obra con la totalidad histórica.

En consecuencia, el libro analiza la obra de Álvaro García Linera a partir de cuatro momentos, a saber: un momento inicial vinculado a su militancia en el Ejército Guerrillero Tupak Katari (1988-1992); un segundo momento asociado a su prisión en la cárcel de máxima seguridad de Chonchocoro (1992-1997); una tercera etapa en la cual el matemático y sociólogo autodidacta se desempeñará como académico de la Universidad Mayor de San Andrés, UMSA (1997-2005); y finalmente, un momento institucional en el cual se desempeña como vicepresidente de la República de Bolivia (2006-2017).

En cada uno de los momentos señalados, el texto analiza el contexto histórico boliviano, los principales focos de conflictividad política, los ciclos de movilizaciones y protestas sociales, el despliegue de las fuerzas sociales y políticas emancipatorias del país hermano. También se detiene en sus influencias teóricas, en las interpretaciones que va realizando de la obra de Karl Marx, en las polémicas y debates que despliega en el seno de la izquierda, en sus intervenciones públicas y vinculaciones con organizaciones y movimientos sociales, en sus principales publicaciones y producciones escritas; y por supuesto, en las modulaciones que van adquiriendo las categorías de Estado y Comunidad en cada uno de estos momentos. La detención y seriedad con que Tomás Torres realiza el análisis de la obra de Álvaro García Linera, es del todo recomendable para quienes se interesen por comprender el trabajo teórico y político del actual vicepresidente, y para quienes deseen conocer algunos acontecimientos y coyunturas relevantes de la historia contemporánea de Bolivia.

En segundo orden, el texto analiza e interpreta la obra de Álvaro García Linera, como la de un intelectual revolucionario adscrito a la corriente del marxismo crítico latinoamericano. Es decir, vinculado a una perspectiva del marxismo que se caracteriza por ser creativa y herética, por poner en diálogo los planteamientos del filósofo de Tréveris, con la compleja y densa realidad de Bolivia y América Latina. Su obra se enlaza con la de José Carlos Mariátegui y René Zavaleta Mercado, por nombrar a dos grandes referentes del marxismo crítico en la región andina.

Su trabajo se asocia a un marxismo que se inscribe en las luchas concretas de los/as trabajadores/as, campesinos/as e indígenas; un marxismo militante, comprometido corporal 
e intelectualmente con los levantamientos populares, las causas revolucionarias y las luchas emancipatorias. Tal como nos lo revela el libro, la militancia de García Linera en el Ejército Guerrillero Tupac Katari, su encarcelamiento en Choconcoro, su vinculación y actividad en el Grupo Comuna, su respaldo político a las guerras del gas (2000) y del agua (2003) y su vinculación al Movimiento al Socialismo, así lo demuestran. El marxismo latinoamericano del actual vicepresidente, debe situarse lejos de un marxismo de escritorios, academias, bibliotecas y oficinas burocráticas.

El marxismo latinoamericano en que se inscribe la obra de Álvaro García Linera, es un marxismo de la praxis, que articula dialécticamente teoría y práctica; que modula trabajo intelectual, político, investigativo, educativo y práctico; y adicionalmente, lejos de las perspectivas dogmáticas del siglo XX, es un marxismo que se posiciona desde una opción plebeya, desde las comunidades, naciones, pueblos y clases coloniales, explotadas y oprimidas.

Finalmente, y como tercera gran temática, el libro profundiza en el análisis dinámico que realiza Álvaro García Linera en torno a los conceptos de Estado y Comunidad. Con respecto al complejísimo problema del Estado en Bolivia y América Latina, se deslizan conceptualizaciones asociadas a la fetichización del poder; a la condensación de la correlación de fuerzas sociales; al monopolio de lo común; al Estado aparente y su cáscara de hegemonía; y por supuesto, la idea del Estado como eje articulador de lo plurinacional. Y con respecto al problema de la comunidad, se bosquejan densas trazas donde se vincula a formas de producción no-capitalistas; al trabajo vivo como exterioridad del capital y/o fuerza creadora de todo valor; los movimientos sociales como formas comunitarias capaces de oponerse al modelo neoliberal; y los planteamientos del socialismo comunitario, que entremezclan formas no capitalistas de producción con formas post-capitalistas.

Sin lugar a dudas, Comunidad y Estado en Álvaro García Linera. Un análisis a través de sus lugares de enunciación (1988 - 2017) es un libro de referencia obligatoria para quienes pretenden aproximarse a una comprensión actual del marxismo crítico latinoamericano, de la historia contemporánea de Bolivia, de la historia de los intelectuales revolucionarios en América Latina, y por supuesto, de la obra de Álvaro García Linera. Adicionalmente, creemos que el libro, es un esfuerzo intelectual y político por alimentar memorias de lucha y 
Revista de la Academia/ISSN 0719-6318

Volumen 28/Primavera 2019

proyectos emancipatorios, compromisos que escasean en las lógicas universitarias de cuño neoliberal. 